\title{
Flavonoid Profiling and Biosynthetic Gene Expression in Flesh and Peel of Two Tomato Genotypes Grown under UV-B-Depleted Conditions during Ripening
}

\author{
Deborah Giuntini, ${ }^{\dagger}$ Valerio Lazzeri,${ }^{\dagger}$ Valentina CalvenZani, ${ }^{\ddagger}$ \\ Chiara Dall'Asta,${ }^{\S}$ Gianni Galaverna, ${ }^{\S}$ Chiara Tonelli, ${ }^{\ddagger}$ \\ Katia Petroni, $* *$ and AnNamaria Ranieri* ${ }^{*} \dagger$
}

\begin{abstract}
Dipartimento di Chimica e Biotecnologie Agrarie, Università degli Studi di Pisa, Via San Michele Degli Scalzi 2, 56124 Pisa, Italy, Dipartimento di Scienze Biomolecolari e Biotecnologie, Università degli Studi di Milano, Via Celoria 26, 20133 Milano, Italy, and Dipartimento di Chimica Organica e Industriale, Università degli Studi di Parma, Viale Usberti 17/A 43100 Parma, Italy
\end{abstract}

\begin{abstract}
The effect of shielding solar ultraviolet $B$ radiation on the accumulation of some flavonoids and their precursor hydroxycinnamic acids in tomato (Solanum lycopersicum) was evaluated by liquid chromatography-electrospray ionization tandem mass spectrometry (LC-ESI-MS/MS). In particular, flesh and peel of two tomato hybrids, DRW 5981 and Esperanza, were separately analyzed. The hybrids have been chosen for their different responses to the light, since it was previously reported that they show different pigmentation and opposite behavior under UV-B in terms of carotenoids and ascorbic acid content at different ripening stages. To determine the effect of UV-B radiation during tomato ripening, we also measured the expression of some flavonoid biosynthetic genes by realtime reverse transcription-polymerase chain reaction (RT-PCR) analysis. The results allowed us to conclude that UV-B radiation deeply and differentially affects the content of the considered flavonoids and hydroxycinnamic acids as well as the expression of some of their biosynthetic genes in both flesh and peel during the ripening process. On the other hand, the collected data clearly showed that this influence varies between different genotypes. We conclude that the use of specific plastic covers able to eliminate UV-B radiation may be an environmentally friendly approach to modulate the expression of structural genes and, in turn, to enhance healthy antioxidant compounds in fruits of specific tomato cultivars.
\end{abstract}

KEYWORDS: Flavonoids; hydroxycinnamic acids; flavonoid biosynthesis genes; Solanum lycopersicum; UV-B radiation; real-time $\mathrm{RT}$-PCR

\section{INTRODUCTION}

Flavonoids are plant polyphenolic compounds. Among them, flavonols are well-known health-protecting components in the human diet, as a result of their high antioxidant capacity $(1,2)$. A number of epidemiological studies suggests that they have a protective effect against cardiovascular diseases (3), cancer (4), and age-related diseases (5). There is also evidence that flavonoids may exert their effect by interfering with signaling pathways (1). More particularly, naringenin chalcone and rutin, the most abundant flavonoids in tomato fruit, have shown

* Corresponding authors: (A.R.) telephone +39 (0)50 2216605; fax +39 (0)50 2216630; e-mail aranieri@agr.unipi.it; (K.P.) e-mail Katia.Petroni@unimi.it.

${ }^{\dagger}$ Università degli Studi di Pisa.

¥Università degli Studi di Milano.

${ }^{\S}$ Università degli Studi di Parma. important beneficial properties to human health. The first metabolite was proven to show antiallergic activity (6), whereas the second one has long been studied for human healthprotecting properties (7). Due to these beneficial effects, in recent years there has been an increasing interest in developing fruits and vegetables with a high content of such compounds.

Ultraviolet radiation (UV), especially in its B component $(280-320 \mathrm{~nm})$, has become a potential source of serious damage to all living organisms. This damage is particularly great for plants that are not able to avoid UV irradiation on account of their sessile nature. Recently, Suesslin and Frohnmeyer (8) discovered a putative UV-B photoreceptor or, at least, an important component of the UV-B transduction signaling. This finding contributes, together with other important data (9-11), to better clarify the postulated existence of a stress-independent UV-B signaling pathway in plants. On the contrary, it is established that plant phytochromes and cryptochromes are not 
the UV-B photoreceptors, even if UV-A may play a role in UV-B signal transduction (12).

Flavonoids are a class of compounds that are involved in plant response to various stresses, including UV photo-oxidative burst, due to their ability to absorb light in the UV region and to their well-known antioxidative properties $(13,14)$. Furthermore, they accumulate in vacuoles of epidermal cells, most probably acting as a protective shield to the inner cell layers. Nonetheless, UV-B has proven to be an important stimulating factor of two flavonoid biosynthetic enzymes, chalcone synthase (CHS) and chalcone isomerase (CHI) (15). Finally, flavonoid-deficient mutants from Arabidopsis thaliana displayed more sensitivity to excessive UV-B irradiation (16), whereas other mutants characterized by high flavonoid content were shown to be less sensitive than wild type (17). Flavonoids are not the only components involved in the plant response to UV-B radiation; other phenolics, such as hydroxycinnamic acids, are also thought to contribute to the plant natural shielding (18).

The most tomato-characterizing secondary metabolites are carotenoid molecules, which primarily determine the typical red color of the well-ripened fruit. However, tomato fruit and, especially, tomato fruit peel have also proven to be a source of flavonoids. The main flavonoid found in cultivated tomato is naringenin chalcone, but some amounts of quercetin and kaempferol derivatives, such as quercetin rutinoside (rutin) and kaempferol rutinoside, are also produced. Such compounds accumulate in a tissue- and developmental-specific manner, since they are produced almost exclusively in the tomato peel during fruit ripening (19). Rutin was found only in traces in the wellripened flesh, which constitutes $95 \%$ of the fruit.

Northern analysis revealed that in fruit peel of cultivated tomato only the chalcone isomerase-catalyzed step is blocked, whereas most of the pathway appears to be suppressed in fruit flesh $(19,20)$. The $C H S, F 3 H$ and FLS genes (encoding chalcone synthase, flavanone 3-hydroxylase, and flavonol synthase enzymes, respectively) are indeed abundantly expressed in peel tissue, whereas in tomato flesh all three transcripts were undetectable. On the contrary, the $C H I$ transcript is barely detectable in both tissues of cultivated tomato, thus correlating with accumulation of naringenin chalcone in peel tissue but not in flesh $(19,20)$.

Recently, several authors have tried to increase flavonoid content in tomato fruit through a transgenic approach, that is the ectopic expression of flavonoid structural genes $(19,21,22)$ or the overexpression of the $L c 1$ and $C 1$ regulatory genes from maize (23). Other authors proposed a nontransgenic approach using traditional breeding with a wild tomato species, which expresses all flavonoid structural genes, including $\mathrm{CHI}$, in both peel and fruit flesh (20).

In addition to the genetic background of the plants, growing conditions also represent a pivotal factor that affects the antioxidant content of the tomato fruit. UV-B radiation evokes diverse phenotypic responses, including hypocotyl growth inhibition and induction of UV-B-protecting pigmentation, in a variety of plants $(24,25)$. Previous experiments revealed that natural UV-B exerts very different effects on carotenoid content in fruits of different genotypes in tomato (26). In the DRW 5981 hybrid, all carotenoids analyzed, except $\beta$-carotene, were higher than in the absence of UV-B radiation, while an opposite effect was observed in the Esperanza hybrid, since total carotenoids, whose level is normally lower than in DRW 5981, were further decreased by UV-B both in the breaker and in the well-ripe tomato fruits.
Little is known about the possibility of enhancing flavonoids in tomato fruits by modulating light quality. Therefore, in the present research, two commercial tomato plants, DRW 5981 and Esperanza, were grown until complete fruit ripening inside two greenhouses where two different light conditions were used: the first represented by the whole sunlight spectrum and the latter deprived of the UV-B region $(280-320 \mathrm{~nm})(26)$. The fruits harvested at three different ripening stages were analyzed to evaluate the influence of the genotype and UV-B radiation on the content of the most abundant flavonoids and hydroxycinnamic acids. To obtain more insights on the influence of UV-B radiation on the biosynthetic pathway of flavonoids, the expression of some flavonoid structural genes was evaluated. From an applicative point of view, this experimental approach may be a good alternative to modulate the expression of structural genes in flesh and peel, thus influencing the amount of healthy antioxidant compounds in tomato fruits.

\section{MATERIALS AND METHODS}

Chemicals. Caffeic, sinapic, $p$-coumaric, and $o$-coumaric acids as well as quercetin, morin, rutin, and naringenin chalcone were purchased from Extrasynthese (Genay Cedex, France); ferulic acid was purchased from Ega Chemie (Steinhem, Germany). o-Coumaroyl methyl ester was prepared in our laboratory. $\mathrm{NaOH}$ pellets were purchased from Baker (Mallinckrodt Baker, Phillipsburg, NJ). All solvents for flavonoid and hydroxycinnamic acid extraction and quantification were of HPLC grade and were purchased from VWR International and Carlo Erba (Milano, Italy). Chlorophyll $a$ and $b$ were purhased from Sigma-Aldrich (Steinheim, Germany), as was butylated hydroxytoluene. Celite Filter $\mathrm{Cel}$ and magnesium carbonate were purchased from Fluka (Buchs, Switzerland), while all solvents for chlorophyll extraction and quantification were of HPLC grade and were purchased from Baker.

Reagents for RNA extraction (NaAc, LiCl, EDTA, sarcosyl, and phenol/chloroform 1:1) were molecular biology grade and were purchased from Sigma-Aldrich. Primers were of high purity and saltfree (HPSF grade) and were purchased from MWG-Biotech AG (Ebersberg, Germany).

Plant Material and Growth Conditions. Two tomato (Lycopersicon esculentum) genotypes were used: the hybrid Esperanza F1 (previously named DRW 3226) characterized by low lycopene content and the hybrid DRW 5981, characterized by high lycopene content (kindly provided by De Ruiter Sementi).

Seeds of the two tomato genotypes were sown, in plug trays with a peat/perlite $(3: 1 \mathrm{v} / \mathrm{v})$ medium, four times (each separated by 1 week), and the fruits were harvested at the same time at two ripening stages. Plants were grown in a heated glasshouse under natural light conditions, watered daily, and received $20 \mathrm{~N}-20 \mathrm{P}-20 \mathrm{~K}$ soluble fertilizer $\left(1 \mathrm{~g} \mathrm{~L}^{-1}\right)$ once a week. About 45 days after sowing, when the seedlings had reached the stage of four true leaves, the tomato plants were transplanted into pots containing the same medium and fertilized weekly with $24 \mathrm{~N}$ $8 \mathrm{P}-16 \mathrm{~K}$. The tomato plants were kept in the glasshouse (UV-B-free) until 1 week before the breaker stage of the first truss of fruits. The plants were then transferred in May into two plastic tunnels characterized by different light conditions (Figure 1). In the first tunnel, covered by polyethylene film, the plants were subjected to the whole sunlight spectrum conditions (control fruits), whereas in the second tunnel covered by polyethylene film stabilized with the UV-B absorber benzophenone, the plants were kept in the absence of UV-B (UV-Bshielded fruits). Five plants from each cultivar have been used in this experiment. They were kept randomly in the two tunnels to avoid the border effect. The two tunnels were placed in an open field and their longest sides were directed along the west-east direction to allow for uniform exposure of plants to sunlight. Tomato harvesting was performed at the mature green (MG, 35-40 DPA), turning (TU, breaker $+3)$ and red ripe $(\mathrm{RR}$, breaker +7$)$ stages, and the ripeness stage was characterized in accordance with the procedure reported by Grierson and Kader (27). Healthy fruits of comparable dimension were carefully harvested from sunny branches. For both flavonoid and RNA analyses, two samples of flesh and peel were collected separately. Each sample 


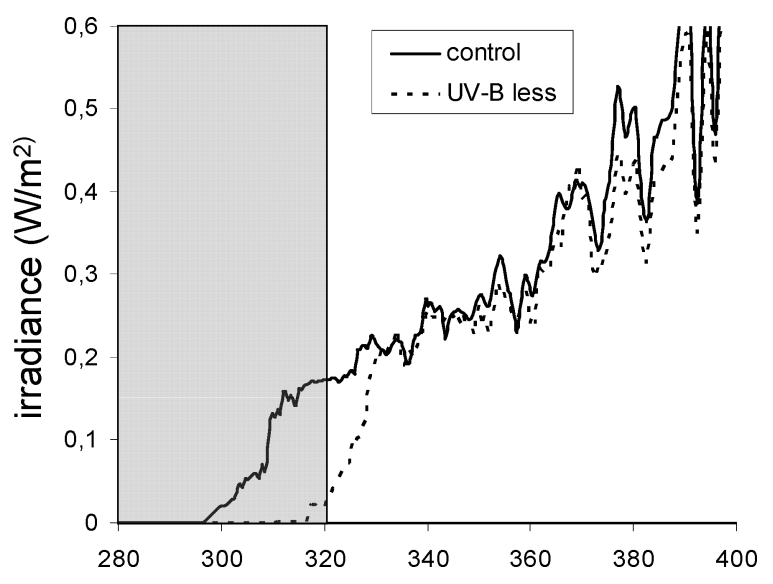

Figure 1. Irradiance spectrum in the UV region under two kinds of polyethylene films used to cover the tunnels where tomato plants have been grown: (-) control (full sunlight); ( $\cdots)$ treatment (UV-B-shielded samples). Irradiance is expressed in watts per square meter. Gray area indicates the UV-B region of the spectrum.

was frozen by liquid nitrogen and stored at $-80^{\circ} \mathrm{C}$ until analysis. Fresh tomatoes were homogenized and biochemical parameters were determined on three groups of fruits at each ripening stage consisting of 20 fruits randomly chosen from each batch.

Extraction of Flavonoids and Hydroxycinnamic Acids. Flavonoid and hydroxycinnamic acids extraction was performed in triplicate, according to Crozier et al. (28) with slight modifications. Flesh and peel from berries were freeze-dried, and then $20 \mathrm{~mL}$ of a $20 \%$ methanol aqueous solution with morin as internal standard $(1 \mu \mathrm{g} / \mathrm{ml})$ was added to $1 \mathrm{~g}$ of sample. After addition of BHT $(0.1 \% \mathrm{w} / \mathrm{w})$ to prevent oxidation, the sample was homogenized with an Ultra-Turrax for 5 $\min$ at $3000 \mathrm{rpm}$ : after centrifugation at $4000 \mathrm{rpm}$ for $5 \mathrm{~min}$, the supernatant was filtered on HPLC filters $(0.45 \mu \mathrm{m})$ and used for HPLC analysis (injection volume, $10 \mu \mathrm{L}$ ).

Quantitative analysis of hydroxycinnamic acids was performed after alkaline hydrolysis in order to obtain the free forms according to Rapisarda et al. (29), as these compounds are preferentially present as glucose or quinic esters in many fruits. For cinnamate analysis, $o$-coumaroyl methyl ester was used as an internal standard.

In particular, alkaline hydrolysis was performed at $25^{\circ} \mathrm{C}$ in the dark for $4 \mathrm{~h}$, by adding $5 \mathrm{~mL}$ of $1 \mathrm{M} \mathrm{NaOH}$ to the supernatant $(10 \mathrm{~mL})$. After neutralization with $1 \mathrm{M} \mathrm{HCl}$, the hydrolyzed fraction was extracted twice with ethyl acetate $(10 \mathrm{~mL})$, the organic solution was pooled and evaporated under vacuum, and the residue was dissolved in methanol $(1 \mathrm{~mL})$ and injected in HPLC (29).

Identification of Flavonoids and Hydroxycinnamic Acids. Reversedphase chromatographic analysis was performed by liquid chromatography-electrospray ionization tandem mass spectrometry (LCESI-MS/MS) technology, by use of a 2695 Alliance separation module equipped with a Spherisorb Jupiter $\mathrm{C}_{18}$ column $(250 \times 4.6 \mathrm{~mm}, 5 \mu \mathrm{m}$ particles), a 996 photodiode array detector (all from Waters, Milford, MA), and a Quattro triple-quadrupole mass spectrometer with an electrospray ionization (ESI) source (Micromass, Manchester, U.K.). Gradient elution was performed with solvent A (HPLC-grade water acidified with $0.2 \%$ formic acid) and solvent B (acetonitrile with $0.2 \%$ formic acid). Flow rate was $1 \mathrm{~mL} / \mathrm{min}$ and the gradient was as follows: 0-20 min, $100 \% \mathrm{~A} ; 20-38 \mathrm{~min}, 60 \% \mathrm{~A}$ and $40 \% \mathrm{~B} ; 38-45 \mathrm{~min}$, $100 \% \mathrm{~A}$. The electrospray probe was operated in the positive ion mode; cone voltage $30 \mathrm{~V}$, capillary voltage $3 \mathrm{kV}$, total ion current scan $100-1500 \mathrm{~m} / z$, scan duration $2 \mathrm{~s}$, intertime $0.2 \mathrm{~s}$, nitrogen flow in spray phase $100 \mathrm{~L} / \mathrm{h}$, and nitrogen flow in desolvation phase $450 \mathrm{~L} / \mathrm{h}$.

Data were acquired by the software Masslynx 4.1 (Waters, Milford, MA). PDA chromatograms $(200-600 \mathrm{~nm}$ scan range) and mass chromatograms $(100-1500 \mathrm{~m} / \mathrm{z}$. scan range) were compared for polyphenol identification according to UV and mass spectra.

Quantification of Flavonoids and Hydroxycinnamic Acids. Quantification was based on UV chromatograms $(360 \mathrm{~nm}$ for flavonoids and $320 \mathrm{~nm}$ for cinnamate, respectively); Calibration experiments were obtained for flavonoids (naringenin chalcone, rutin, and quercetin) in the range of $1-200 \mathrm{mg} / \mathrm{kg}$, showing very good linearity $\left(r^{2}>0.999\right)$. Since a standard was not available for the rutin derivative, it was quantified by use of the rutin calibration curve, with the assumption of the same UV response.

The interday repeatability of the method was proved by performing five injections of standard solutions at three concentration levels (2, 20 , and $100 \mathrm{mg} / \mathrm{Kg}$ ) obtaining RSD values lower than $5.5 \%$ for all the analytes. The limit of quantification $(\mathrm{S} / \mathrm{N}=10: 1)$ were $0.05 \mathrm{mg} / \mathrm{kg}$ for all the flavonoids. The recovery of the method based on the use of morin as internal standard was found to be $95 \% \pm 6 \%$.

Concerning hydroxycinnamic acids (cinnamic, ferulic, sinapic, and caffeic acids), the calibration experiments were performed in the range $0.01-20.0 \mathrm{mg} / \mathrm{kg}$, by using $o$-coumaroyl methyl ester as internal standard. The calibration curves were linear in the range studied, showing correlation coefficients $>0.99$.

The interday repeatability of the method was proved by performing five injections of standard solutions at three concentration levels $(0.5$, 5 , and $10 \mathrm{mg} / \mathrm{kg}$ ): RSD values lower than $4.6 \%$ were obtained for all the analytes. The limit of quantification $(\mathrm{S} / \mathrm{N}=10: 1)$ were $0.01 \mathrm{mg} /$ $\mathrm{kg}$ for all the cinnamate. The recovery of the method based on the use of $o$-coumaroyl methyl ester as internal standard was found to be $95 \%$ $\pm 3 \%$.

Extraction and Quantification of Chlorophylls. Chlorophylls were extracted from liquid nitrogen-ground tomato flesh and peel. The sample was homogenized with an Ultra-Turrax and chlorophylls were extracted with $5 \times 15 \mathrm{~mL}$ of tetrahydrofuran stabilized with $0.01 \%$ BHT, and with both $10 \%(\mathrm{w} / \mathrm{w})$ magnesium carbonate and Celite. Then the combined extract fractions were reduced by two-thirds under vacuum at $35{ }^{\circ} \mathrm{C}$ on a rotary evaporator and partitioned into dichloromethane $(25 \mathrm{~mL})$ and $\mathrm{NaCl}$-saturated water $(15 \mathrm{~mL})$ in a separating funnel. The organic fraction was reduced again to a minimal volume of $\sim 2-4 \mathrm{~mL}$ and the residue was filtered through a $0.22 \mu \mathrm{m}$ HPLC filter and injected into the column (Phenomenex Prodigy LC-18 ODS, $250 \times 4.6 \mathrm{~mm}, 5$ $\mu \mathrm{m}$ with guard column Phenomenex AJO-4287 C-18 ODS).

The analytical separation of chlorophyll extracts was carried out through a HPLC class M10 (Shimadzu) connected to a UV-DAD (SPDM10A). The solvents used for elution were dichloromethane (solvent A) and acetonitrile/hexane/methanol/acetonitrile (4:2:2:2) (solvent B) with a flow rate of $0.8 \mathrm{~mL} / \mathrm{min}$. The gradient was as follows: $0-30$ min, $70 \% \mathrm{~A}$ and $30 \% \mathrm{~B} ; 30-40 \mathrm{~min}, 30 \% \mathrm{~A}$ and $70 \% \mathrm{~B} ; 40-45 \mathrm{~min}$, $2 \% \mathrm{~A}$ and $98 \% \mathrm{~B} ; 45-50 \mathrm{~min}, 70 \% \mathrm{~A}$ and $30 \% \mathrm{~B}$. Chlorophyll $a$ and $b$ peaks identification were performed through comparison of $\mathrm{UV}-\mathrm{vis}$ spectra and retention times of pure standards at 460 and $435 \mathrm{~nm}$, respectively, and quantified accordingly.

RNA Isolation and Real-Time RT-PCR Analysis. Samples of $3 \mathrm{~g}$ of flesh and peel of DRW 5981 and Esperanza cultivars were ground in liquid nitrogen in a mortar, and the powder was transferred in 30 $\mathrm{mL}$ tubes containing $12 \mathrm{~mL}$ of extraction buffer $(100 \mathrm{mM} \mathrm{NaAc}, \mathrm{pH}$ 4.8, $100 \mathrm{mM} \mathrm{LiCl}, 10 \mathrm{mM}$ EDTA, and $1 \%$ sarcosyl) and $12 \mathrm{~mL}$ of phenol/chloroform (1:1). Total RNA was precipitated by addition of 1 volume of $4 \mathrm{M} \mathrm{LiCl}$ to the supernatant; the pellet was dissolved in sterile distilled water and stored at $-80{ }^{\circ} \mathrm{C}$. About $5 \mu \mathrm{g}$ of total RNA was reverse-transcribed by use of RT Superscript II (Invitrogen, Carlsbad, CA). After first-strand cDNA synthesis, the samples were diluted 50-fold. Quantitative real-time RT-PCR analysis was performed by use of the fluorescent intercalating dye SYBR-Green with the iCycler iQ Bio-Rad system according to the manufacturer's protocol, in a final volume of $25 \mu \mathrm{L}$ containing $5 \mu \mathrm{L}$ of 50 -fold diluted cDNA, $0.3-0.5$ $\mu \mathrm{M}$ each primer, and $12.5 \mu \mathrm{L}$ of $2 \times$ iQ SYBR Green Supermix (BioRad Laboratories, Inc., Hercules, CA). As a reference for normalization, we used primers specific for LeEF1 (LeEF1F3 5'-ttgaggctcttgaccagatt$3^{\prime}$ as forward primer and LeEF1R3 $5^{\prime}$-aacattgtcaccagggagtg- $3^{\prime}$ as reverse primer), and relative quantification was analyzed by use of iCycler iQ optical system software version 3.0a (Bio-Rad Laboratories, Inc., Hercules, CA). Specific primers were designed on tomato cDNAs or Unigene sequences showing $>90 \%$ amino acid identity to the petunia CHS, CHI, F3H, F3' $\mathrm{H}$, and FLS proteins and amplicons tested according to parameters outlined in the Bio-Rad iCycler Manual. Forward and reverse primers wereas follows: LeCHSF1, 5'-aaactcttgtccccgatagc- $3^{\prime}$, and LeCHSR1, 5' - ccctagaggttgaaatgcttc- $3^{\prime}$, for CHS; CHI_TOM_F, 


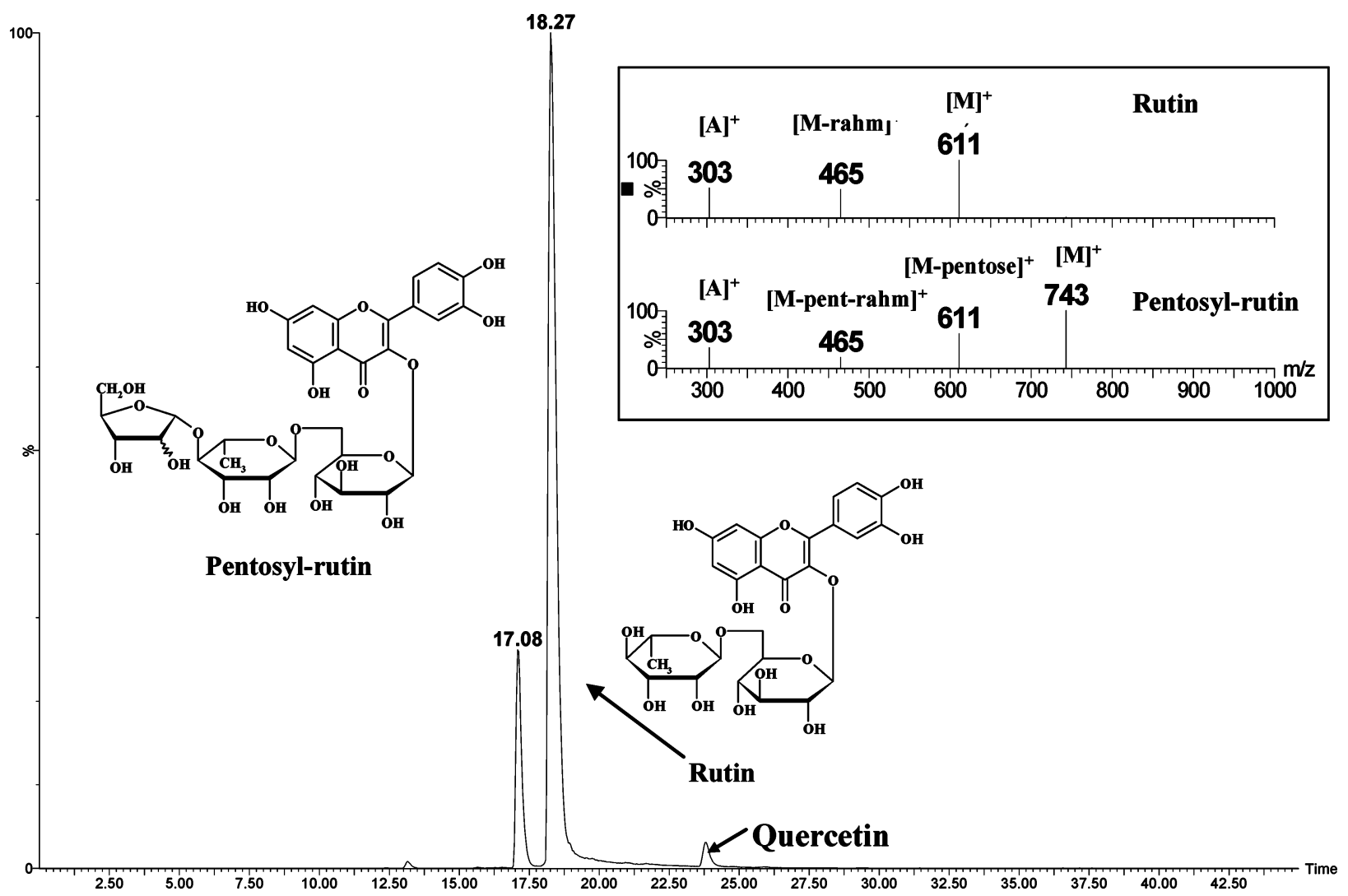

Figure 2. LC-ESI-MS/MS chromatogram of quercetin and its derivatives. The daughter ion spectra obtained for rutin (precursor [M] ${ }^{+}=611$ ) and its pentosyl derivative (precursor $[\mathrm{M}]^{+}=743$ ) are given as well as a tentative structure of the rutin derivative.

$5^{\prime}$-gttttcacaaaccaacagttctgat-3', and CHI_TOM_R, $5^{\prime}$-gaagcagtgctcgattccataat-3', for $\mathrm{CHI}$; LeF3HF1, 5'-tgtccagagcetgaccttac-3' and $5^{\prime}$ cattcttgaacctcccattg- $3^{\prime}$ for $F 3 H$; LeF3'HF1, $5^{\prime}$-aggcttcatccatcaacacc- $3^{\prime}$ and $5^{\prime}$-tcaactttgggctttcacc- $3^{\prime}$ for $F 3^{\prime} H$; and LeFLSF1, $5^{\prime}$-tacagggaagcaaatgagga- $3^{\prime}$ and $5^{\prime}$-cattcttgaacctcccattg- $3^{\prime}$ for $F L S$.

The protocol used was as follows: $95^{\circ} \mathrm{C}$ for $3 \mathrm{~min}$, followed by 40 cycles of $95{ }^{\circ} \mathrm{C}$ for $15 \mathrm{~s}, 58{ }^{\circ} \mathrm{C}$ for $45 \mathrm{~s}$, and $60{ }^{\circ} \mathrm{C}$ for $15 \mathrm{~s}$. A melt curve analysis was performed following every run to ensure a single amplified product for every reaction. Relative quantification of the target RNA expression level was performed by the comparative $\mathrm{Ct}$ method (User Bulletin 2, ABI PRISM7700 Sequence Detection System, December 1997; Perkin-Elmer Applied Biosystems) in which the differences in the $\mathrm{Ct}$ (threshold cycle) for the target RNA and endogenous control RNA, called $\Delta \mathrm{Ct}$, were calculated to normalize for the differences in the total amount of cDNA present in each reaction and the efficiency of the reverse transcription. Finally, the target RNA expression level was obtained from the expression $2^{-\Delta \Delta \mathrm{Ct}}$ and expressed relative to a calibrator (flesh of $\mathrm{MG}$ fruits grown under control conditions, except where differently stated). Bars represent standard deviations of $\Delta \Delta \mathrm{Ct}$ values obtained from measurements performed in triplicate. To verify that low expression levels in flesh were not due to background level, a proportional reduction in the relative expression level/threshold cycle was checked by use of four serial dilutions $(0$, $1-, 4-$, and 10-fold) of the cDNA samples from flesh of DRW 5981 and Esperanza control fruits.

\section{RESULTS AND DISCUSSION}

The aim of this study was to evaluate the effect of UV-B depletion on the content of some health-beneficial phenolic compounds, such as flavonoids and hydroxycinnamic acids, in tomato flesh and peel during fruit ripening. UV-B has proven to be an important stimulating factor of two flavonoid biosynthetic enzymes, CHS and CHI, so to assess the direct effect of UV-B depletion on the expression of the structural genes involved in flavonoid biosynthesis, total RNA was extracted and analyzed through real-time RT-PCR.
Effect of UV-B Depletion on Phenolic Biosynthesis in Peel and Flesh. The two tomato genotypes Esperanza and DRW 5981, previously characterized as containing low and high lycopene content, respectively (26), showed different responses to the presence (control fruits) or the absence of UV-B radiation (UV-B-shielded fruits) during the three considered ripening stages: mature green (MG), turning (TU), and red ripe (RR). The content of the most abundant flavonoids, such as naringenin chalcone, quercetin, and rutin, was evaluated in flesh and peel separately, in order to determine whether UV-B light differently affected the flavonoid biosynthesis in these two tissues.

Chromatographic analyses also revealed the presence of a relevant amount of a quercetin derivative, which was identified by mass spectrometric measurements as a quercetin-3-Opentosylrutinoside, as reported in Figure 2. Several authors have already reported the occurrence of conjugation products of rutin with arabinose or xylose $(30,31)$, but unfortunately the identification of the pentose residue was not possible by ESI triple-quadrupole fragmentation (32). Nonetheless, the putative identification of tomato metabolites by mass spectrometry was recently proposed by Moco et al. (33) as an alternative to isolation and NMR characterization. Moreover, very recently Slimestad et al. (34) reported the occurrence in tomato of a quercetin derivative, which was identified as quercetin 3-O[2"- $O$-apiofuranosyl-6"- $O$ - $(R)$-rhamnopyranosylglucopyranoside] on the bases of chromatographic (HPLC) and spectral (UV, high-resolution MS, ${ }^{1} \mathrm{H}$ and $\left.{ }^{13} \mathrm{C} \mathrm{NMR}\right)$ data. The MS and MS/ MS data obtained in the present work for the quercetin derivative are consistent with those reported by Slimestad et al. (34). Nonetheless, in the absence of NMR data, we are not able to univocally identify the pentosyl group as apiose; thus we prefer to stick with the more generic name quercetin 3- $O$-pentosylrutinoside. 


\section{DRW 5981}

\section{A FLAVONOID CONTENT}

PEEL
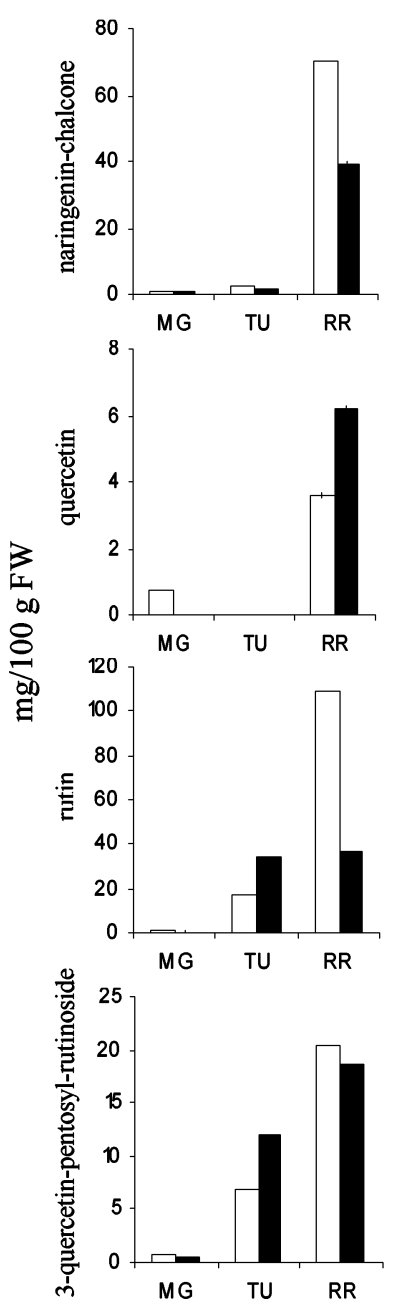

FLESH
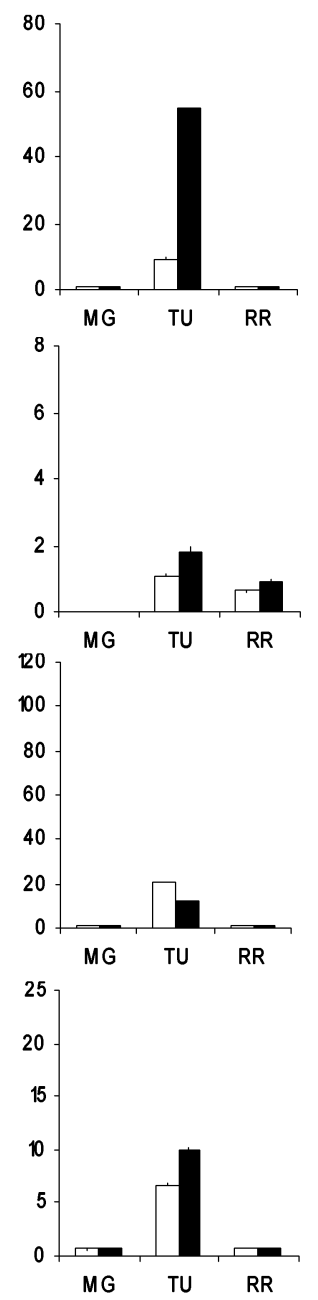

B GENE EXPRESSION

PEEL

FLESH
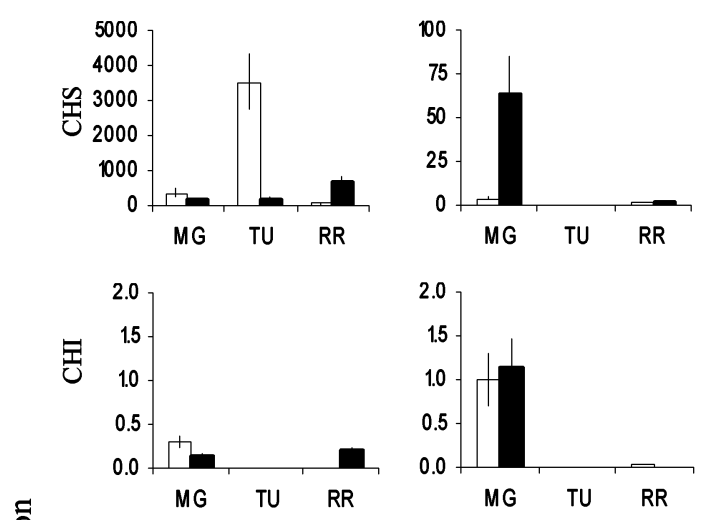

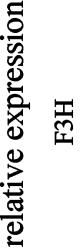
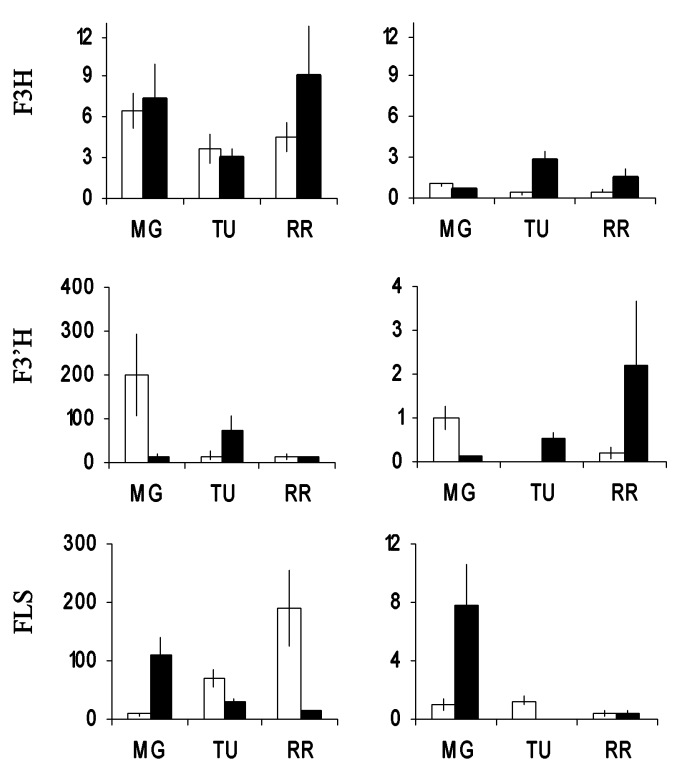

Figure 3. Flavonoid content and mRNA steady-state levels of flavonoid structural genes in flesh and peel of DRW 5981 fruits grown in the presence and deprivation of UV-B. (A) Content of the different flavonoids analyzed in flesh and peel of DRW 5981 cv. Open and solid columns represent control fruits and UV-B-shielded fruits respectively. Data are expressed in milligrams per $100 \mathrm{~g}$ of fresh weight. Bars represent standard errors of measurements performed in triplicate. (B) Relative expression levels of $\mathrm{CHS}, \mathrm{CHI}, \mathrm{F} 3 \mathrm{H}, \mathrm{F} 3 \mathrm{H}$, and FLS structural genes in genotype DRW 5981 with LeEF1 as endogenous control. The transcript amount in the flesh of MG fruits was arbitrarily set to 1 and served as calibrator for relative expression levels in each transcript analysis. Open and solid columns represent control fruits and UV-B-shielded fruits, respectively. Bars represent standard errors of measurements performed in triplicate. Abbreviations: MG, mature green; TU, turning; RR, red ripe.

The accumulation pattern of flavonoid in both flesh and peel of the two genotypes was differently influenced by the ripening stage and the light conditions (Figures 3A and 4A).

The maximum overall flavonoid concentration in tomato peel reached, in the present work, $200 \mathrm{mg} / 100 \mathrm{~g}$ of fresh weight (Table 1). These data are at least 1 order of magnitude higher than those commonly reported for tomato whole fruits $(35,36)$, but several authors already reported similar levels of phenolic compounds for tomato peel $(37,38)$.

Similarly to what was previously found for carotenoids on the whole fruits (26), Esperanza showed in the peel a lower amount of total flavonoids than DRW 5981, thus indicating a lower capability of this genotype to accumulate both carotenoids and flavonoids (Table 1). Furthermore, both genotypes showed an accumulation pattern of these polyphenolic compounds in the peel similar to that observed for carotenoids in the whole control fruit (26).

In particular, under control conditions, DRW 5981 showed an increase of flavonoid content in the peel during ripening, reaching the highest amount at the RR stage (Table 1, Figure 3A). The same trend was shown also for the UV-shielded fruits, although the overall analyte concentrations were lower than those found for control samples. On the contrary, a transient large accumulation of flavonoids in flesh was observed for both DRW 5981 control and UV-shielded fruits, with a maximum level at TU stage for all the analytes. With the exception of rutin, the levels of all flavonoids were up-regulated mostly in the UV-B-shielded conditions: this genotype seems to be able to synthesize higher amounts of flavonoids in the flesh, at the TU stage in the absence of UV-B, with the exception of rutin, whose content was higher in the control fruits (Figure 3A). These results are in agreement with those found by other authors, who reported an increase of glycosylated and B-ring polysubstituted flavonoids in Marchantia polymorpha and rice during growth under enhanced UV-B radiation $(39,40)$.

Differently from what was observed for DRW 5981, in the peel of Esperanza genotype a different accumulation trend for flavonoids was observed in control and UV-shielded fruits 


\section{ESPERANZA}

\section{A FLAVONOID CONTENT}
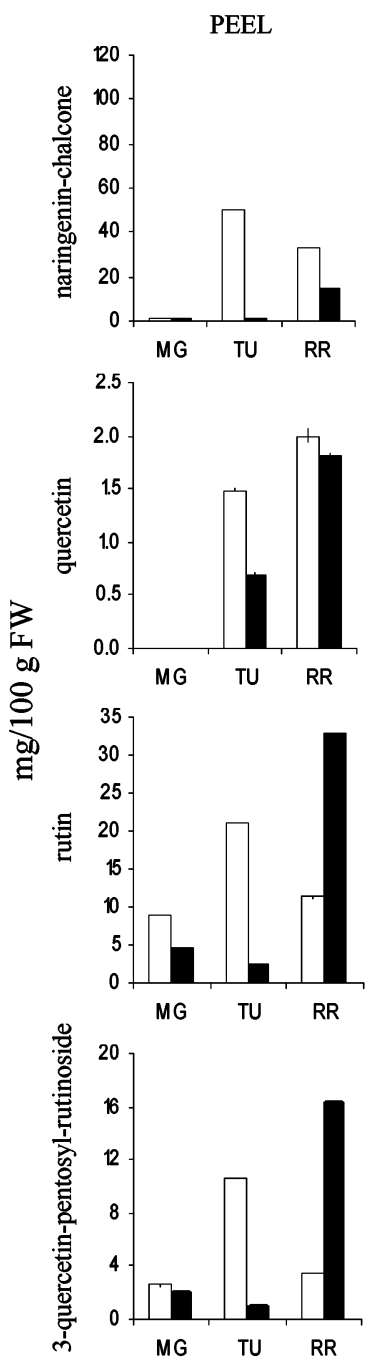

FLESH
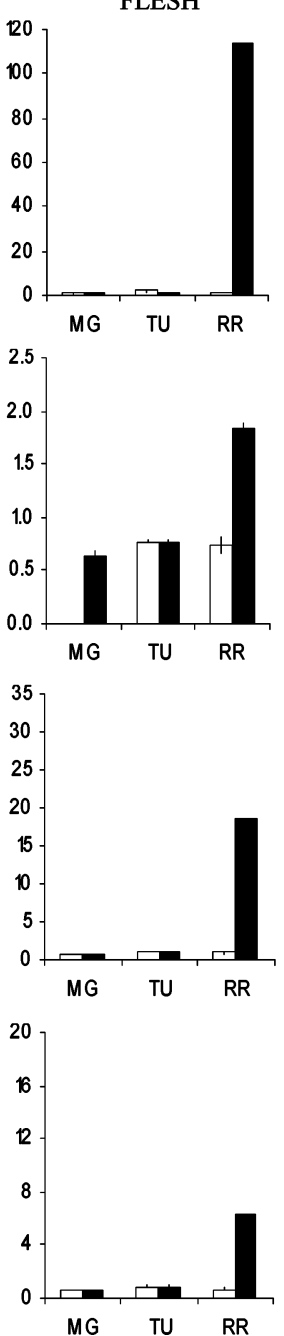

\section{B GENE EXPRESSION}

PEEL
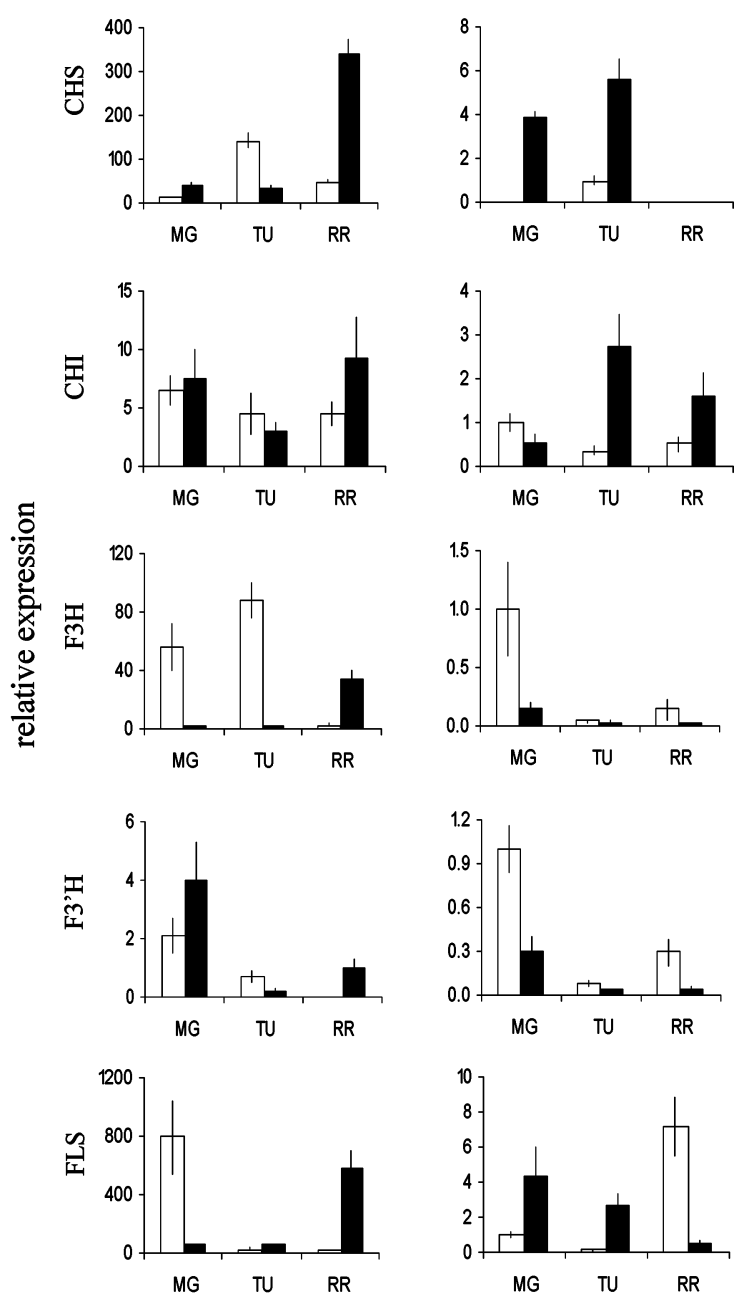

Figure 4. Flavonoid content and mRNA steady-state levels of flavonoid structural genes in flesh and peel of Esperanza fruits grown in the presence and deprivation of UV-B. (A) Content of the different flavonoids analyzed in flesh and peel of Esperanza. Open and solid columns represent control fruits and UV-B-shielded fruits, respectively. Data are expressed in milligrams per $100 \mathrm{~g}$ of fresh weight. Bars represent standard errors of measurements performed in triplicate. (B) Relative expression levels of $\mathrm{CHS}, \mathrm{CHI}, \mathrm{F} 3 \mathrm{H}, \mathrm{F} 3 \mathrm{H}$, and $\mathrm{FLS}$ structural genes in genotype Esperanza with LeEF1 as endogenous control. The transcript amount in the flesh of MG fruits was arbitrarily set to 1 and served as calibrator for relative expression levels in each transcript analysis, except in the case of $\mathrm{CHS}$, where its transcript level in the flesh of TU fruit was used as calibrator. Open and solid columns represent control and UV-B-shielded fruits, respectively. Bars represent standard errors of measurements performed in triplicate. Abbreviations: MG, mature green; TU, turning; $R R$, red ripe.

(Figure 4A). In particular, in the control samples all analytes were present in higher amounts at the TU stage, except quercetin, whereas in the UV-B-shielded samples the highest flavonoid concentration was found at RR stage. Although naringenin chalcone and quercetin were found at a higher concentrations in control fruits at RR stage, rutin and its pentosyl derivative reached their highest amounts in UV-B-shielded fruits at the same stage (Figure $\mathbf{4 A}$ ).

Finally, no differences between UV-B-shielded and control flesh appeared in Esperanza until the RR stage. On the contrary, at this stage in the flesh of UV-B shielded fruits, a much higher amount of flavonoids was found in comparison with the control fruits (Figure 4A).

Flavonoid precursors, such as $p$-coumaric acid and other hydroxycinnamic acids, were also analyzed. In DRW 5981 and Esperanza fruits (Figure 5), caffeic acid was the most abundant hydroxycinnamic acid in both flesh and peel, while the sinapic acid content was nearly negligible. Moreover, differently from flavonoids, the overall content of these compounds did not appear to be dramatically higher in peel than in flesh.

During the ripening process, in the peel of DRW 5981 control fruits (Figure 5A), all hydroxycinnamic acids, with the exception of sinapic acid, were found in higher amounts in control fruits than in UV-B-shielded ones at the RR stage, while in the flesh the highest amount of these compounds was found at the RR stage under UV-B-deprived conditions.

Esperanza peel and flesh showed a generally similar trend in the accumulation of hydroxycinnamic acids in control fruits (Figure 5B). Accordingly, all the analytes decreased in the peel to a barely detectable level at the RR stage, with the exception of sinapic acid. This compound, indeed, was found in low amount only at the TU stage. A similar result was found in the flesh for sinapic, caffeic, and ferulic acids, although they were still detectable at the RR stage. 
Table 1. Total Flavonoids and Chlorophylls Content and Fresh Weight of Tomato Fruits (DRW 5981 and Esperanza) Grown under Different Light Conditions

\begin{tabular}{|c|c|c|c|c|c|c|c|c|}
\hline stage & tissue & \multicolumn{2}{|c|}{ total flavonoids ${ }^{a, b}$} & \multicolumn{2}{|c|}{ chlorophyll $a+b^{b}$} & stage & \multicolumn{2}{|c|}{ fresh weight/fruit ${ }^{c}$} \\
\hline \multicolumn{9}{|c|}{ DRW 5981} \\
\hline$M G$ & peel & $3.37 \mathrm{e}$ & $1.88 f$ & $29.32 \mathrm{a}$ & $12.97 \mathrm{~b}$ & $M G$ & $103.1 \mathrm{a}$ & $109.8 \mathrm{a}$ \\
\hline TU & peel & $26.84 \mathrm{~d}$ & $47.74 \mathrm{c}$ & $4.26 \mathrm{~d}$ & $5.43 \mathrm{c}$ & TU & $102.2 \mathrm{a}$ & $111.3 \mathrm{a}$ \\
\hline $\mathrm{RR}$ & peel & $202.85 \mathrm{a}$ & $101.38 \mathrm{~b}$ & nd & nd & $\mathrm{RR}$ & $101.3 \mathrm{a}$ & $114.9 \mathrm{a}$ \\
\hline$M G$ & flesh & $2.53 \mathrm{~d}$ & $2.43 d$ & $2.58 \mathrm{a}$ & $1.65 b$ & & & \\
\hline $\mathrm{RR}$ & flesh & $3.10 \mathrm{c}, \mathrm{d}$ & $3.40 c$ & nd & nd & & & \\
\hline$M G$ & peel & $12.53 \mathrm{~d}$ & $8.15 e$ & $4.96 \mathrm{a}$ & $3.39 b$ & $M G$ & $89.5 \mathrm{a}$ & $90.6 \mathrm{~b}$ \\
\hline TU & peel & $83.37 \mathrm{a}$ & $5.73 f$ & $0.09 \mathrm{~d}$ & $0.37 \mathrm{c}$ & TU & $91.0 \mathrm{a}$ & $93.0 a, b$ \\
\hline $\mathrm{RR}$ & peel & $50.25 \mathrm{c}$ & $65.47 \mathrm{~b}$ & nd & nd & $\mathrm{RR}$ & $92.7 \mathrm{a}$ & $95.5 \mathrm{a}$ \\
\hline$M G$ & flesh & $1.97 \mathrm{e}$ & $3.26 \mathrm{c}, \mathrm{d}$ & $1.02 b$ & $1.37 \mathrm{a}$ & & & \\
\hline TU & flesh & $4.73 b$ & $3.84 \mathrm{C}$ & $0.20 \mathrm{~d}$ & $1.02 \mathrm{C}$ & & & \\
\hline
\end{tabular}

\footnotetext{
${ }^{a}$ Total flavonoids are the sum of naringenin chalcone, quercetin, rutin, and quercetin 3-0-pentosylrutinoside. ${ }^{b}$ Total flavonoids and chlorophylls values are expressed as milligrams per $100 \mathrm{~g} \mathrm{FW}$ and are the mean \pm standard error of three determinations. ${ }^{c}$ The fresh weight per fruit values are expressed in grams per fruit and are the mean \pm standard error of five determinations. Means followed by different letters are significantly different, $p \leq 0.05$ according to LSD test. Abbreviations: MG, mature green; TU, turning; RR, red ripe; nd, not detected.
}

This decrease in hydroxycinnamic acids in the Esperanza control peel did not correspond to a comparable decrease on flavonoids. These data actually support a lack of accumulation of hydroxycinnamates due to a lower rate of synthesis. As cinnamates are precursors for flavonoid and lignin production, their decrease during ripening can be reasonable (Figure 6).

Regarding the effect of UV-B deprivation, Esperanza peel showed a dramatic accumulation in UV-B shielded conditions but not to the same extent seen for flavonoids, while the flesh showed the trend of increasing hydroxycinnamic acid content in the same conditions but only at RR stage (Figure 5B).

We also reported in Table 1 total chlorophyll $(a+b)$ content during ripening in both genotypes grown with or without solar UV-B radiation. UV-B exposure generally tended to be significantly beneficial to chlorophyll accumulation in DRW 5981, while the opposite effect has been observed in Esperanza fruits.

Concerning the mean fresh weight per fruit, UV-B exposure had only a slight detrimental effect in DRW 5981 at the RR stage, while in the other cases no statistically significant differences were observed between control and UV-B-shielded fruits.

Effect of UV-B Depletion on Flavonoid Gene Expression in Peel and Flesh. To clarify the molecular basis of the differences in flavonoids observed in the presence or absence of UV-B, a parallel analysis of the steady-state levels of $C H S$, $C H I, F 3 H, F 3^{\prime} H$, and $F L S$ genes was performed by real-time RT-PCR in flesh and peel of both DRW 5981 and Esperanza fruits at the same ripening stages considered for the biochemical analysis.

Previous Northern analyses showed that in cultivated tomatoes most of the pathway appeared to be suppressed in fruit flesh, whereas only in peel was the $C H I$ transcript barely detectable $(19,20)$. Using a more sensitive technique, our analysis revealed that all structural genes, although at low levels, were expressed in the flesh of both genotypes at least in one developmental stage and that in control fruits of both genotypes most structural genes analyzed were in general highly more expressed in peel than in flesh (Figures 3B and 4B). This result is in accordance with the flavonoid analysis of both DRW 5981 and Esperanza genotypes, showing the accumulation of flavonoids more prevalently in peel tissue than in flesh but not completely absent in this latter tissue (Figures $\mathbf{3 A}$ and $\mathbf{4 A}$ ). Moreover, as elsewhere reported for Arabidopsis thaliana (41), these results indicate that in the flesh of the two genotypes the analyzed genes were all coexpressed and translated into a sufficient amount of active enzyme characterized by a sufficiently long half-life to allow this tissue to enrich itself in flavonoid metabolites at the TU stage.

In particular, in the peel of DRW 5981 control fruits (Figure 3B), transcript analysis revealed that all structural genes were expressed in almost all ripening stages and at much higher level in comparison to flesh, except the $\mathrm{CHI}$ gene, which showed a 3-fold lower transcript level and, similarly to flesh, a barely detectable level in the subsequent stages. Furthermore, all structural genes, except $F L S$, showed the highest transcript level at the MG or TU stage. In particular, the very high level of the CHS transcript at TU stage and the concomitant low level of the $C H I$ mRNA (Figure 3B) may account for the accumulation of naringenin chalcone at the RR stage of control fruits (Figure 3A). On the other hand, the very high expression level of the downstream structural genes, particularly $F 3^{\prime} H$ and FLS (Figure 3B), suggests that the intermediate naringenin produced by $\mathrm{CHI}$ may be very efficiently converted to the end products quercetin and particularly rutin by the enzymes of the subsequent steps.

In the flesh of DRW 5981 control fruits (Figure 3B), all structural genes, with the exception of FLS, showed an early activation at MG stage and they were barely or not detectable in the following stages. Consistent with this, a transient greater accumulation of flavonoids was observed in flesh at TU stage compared to the other stages (Figure 3A).

In the peel of Esperanza control fruits (Figure 4B), all genes analyzed, including $\mathrm{CHI}$, appeared to be more expressed than in flesh and most of them, except $C H I$, showed a peak of expression at the MG $\left(F 3^{\prime} H\right.$ and $\left.F L S\right)$ or TU stages ( $C H S$ and $\mathrm{F} 3 \mathrm{H}$ ), thus correlating with the peak of flavonoid accumulation observed in the peel of Esperanza at TU stage (Figure 4A).

Finally, in control flesh of Esperanza fruits (Figure 4B) most structural genes, except $F L S$, also showed a higher transcript level at the MG or TU stages (Figure 4B). However, in this tissue the CHS gene was not expressed at the MG stage but was transiently detectable only at the TU stage, thus correlating with the delayed and lower flavonoid accumulation observed in flesh of Esperanza compared to DRW (Figure 4A).

Overall, these data indicate that the expression of structural 


\section{HYDROXYCINNAMIC ACID CONTENT}

A DRW 5981

FLESH
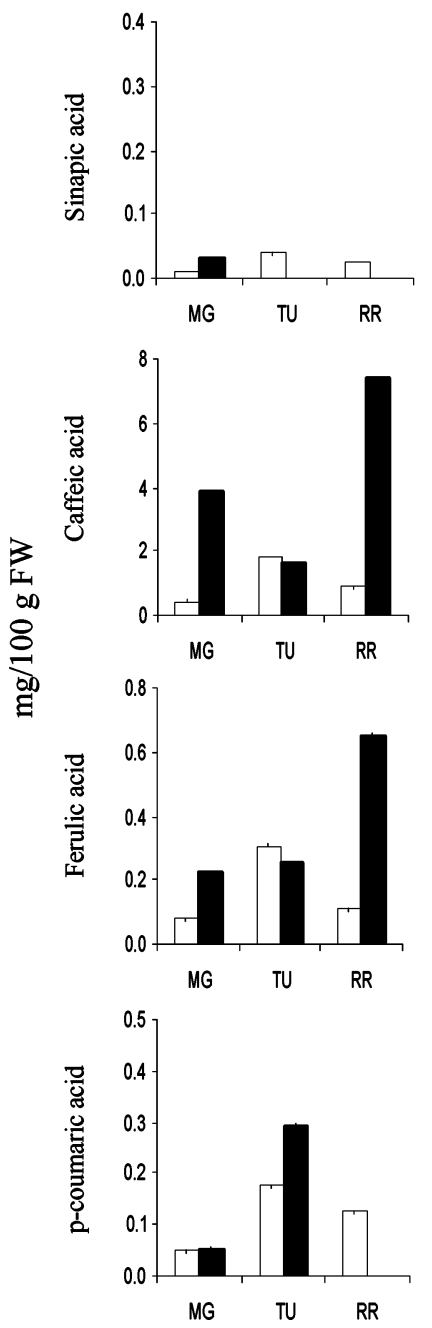

PEEL
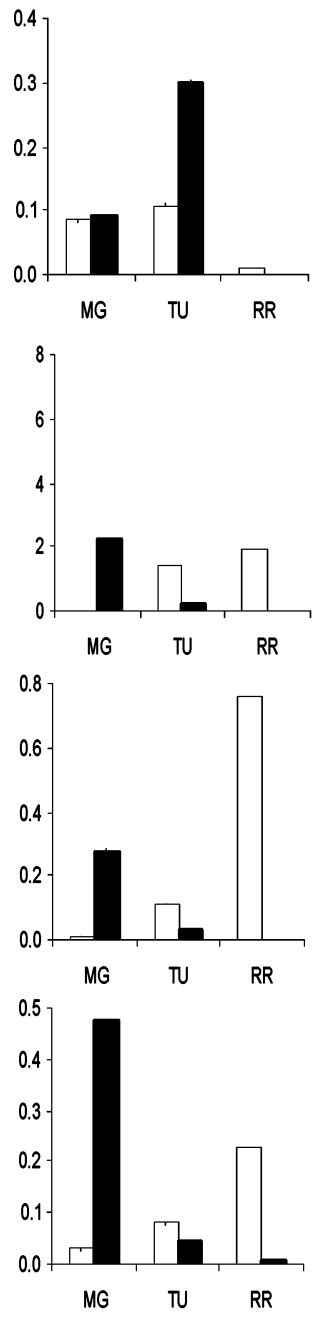

B ESPERANZA

FLESH

PEEL
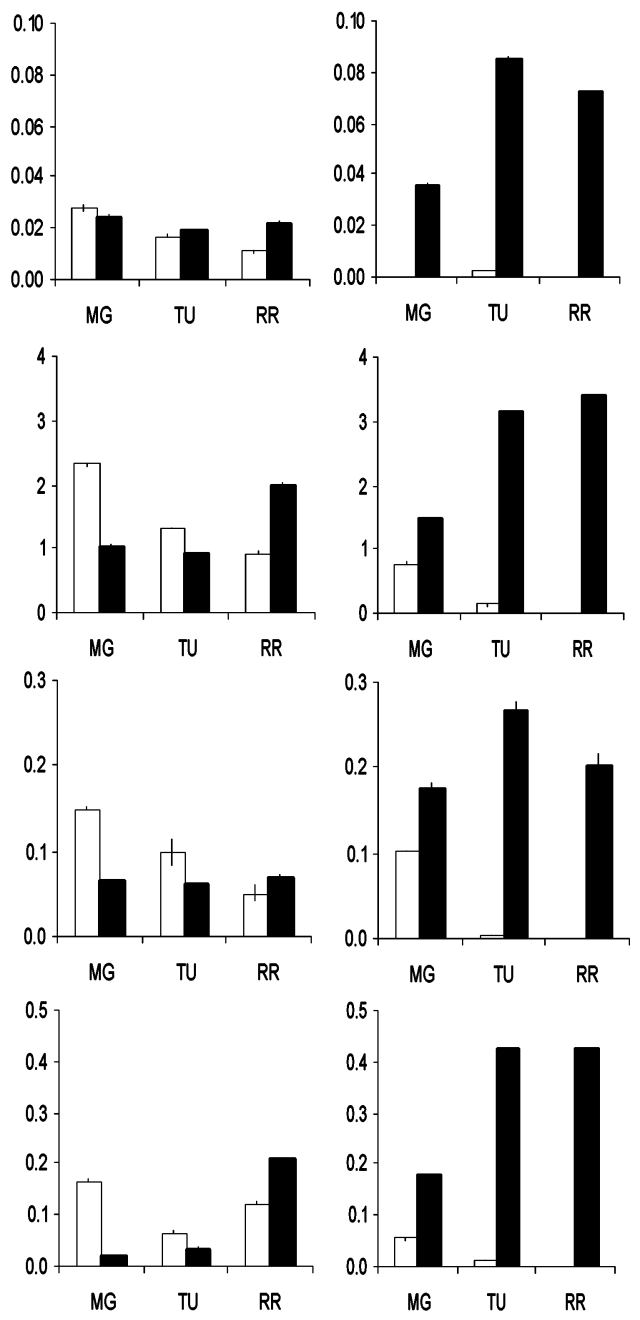

Figure 5. Hydroxycinnamic acid content in flesh and peel of (A) DRW 5981 and (B) Esperanza fruits. Open and solid columns represent control fruits and UV-B-shielded fruits respectively. Data are expressed in milligrams $/ 100 \mathrm{~g}$ of fresh weight. Bars represent standard errors of measurements performed in triplicate. Abbreviations: MG, mature green; TU, turning; RR, red ripe.

genes is regulated during fruit ripening, so that many of them are more expressed at the MG or TU stages in both tissues (Figures 3B and 4B) and that the higher early activation of structural genes at these stages may be important to prepare the multienzymatic complexes in which the flavonoid biosynthetic enzymes are probably organized $(42,43)$, in order to activate the synthesis of intermediate metabolites and final products during the TU stage.

The great accumulation of the precursor naringenin chalcone and the little $\mathrm{CHI}$ expression in both flesh and peel of the two genotypes also led us to hypothesize the existence of an alternative type of this latter enzyme, as already reported in Ralston et al. (44) for tomato (AY348871 and LEtuc02-1021.8002), which could circumvent the CHI limiting step. Moreover, the accumulation of naringenin chalcone could also be explained by the presence of another CHS enzyme, such as the UV-B- and pathogen-induced form of CHS, HvCHS2, identified in barley (45). This enzyme is characterized by an unusual substrate preference for caffeoyl-CoA and feruloyl-CoA instead of 4-coumaroyl-CoA. This could result in a higher quercetin and rutin amount, because caffeoyl-CoA as CHS substrates would lead to the production of eriodictyol chalcone, a chalcone with two dihydroxylic substitutions on B ring as quercetin (Figure 6). Interestingly, in addition to the $C H S$ gene we analyzed (SGN-U316359), two other CHS sequences are present in the tomato database (SGN-U316149 and SGNU323393), whose predicted proteins show amino acid substitutions in the highly conserved region surrounding the active site (46), similarly to what seen for HvCHS2 (45). Moreover, recent findings from Schijlen et al. (22) support these hypotheses, since the ectopic expression of the grape stilbene synthase gene in tomato fruit led to the production of resveratrol and its glucoside at the expense of naringenin chalcone but not of rutin.

Regarding the effect of UV-B deprivation, in the DRW 5981 peel tissue the analyzed genes were prevalently down-regulated in UV-B-shielded fruits (Figure 3B). This down-regulation, particularly the greatly diminished $C H S$ transcription level, was reflected in the overall lower flavonoid content in the UV-Bshielded peel.

Interestingly, in DRW 5981 flesh, all these genes except $C H I$ were more expressed in UV-B-shielded fruits than in control ones, with the CHS gene showing an expression more than 15 


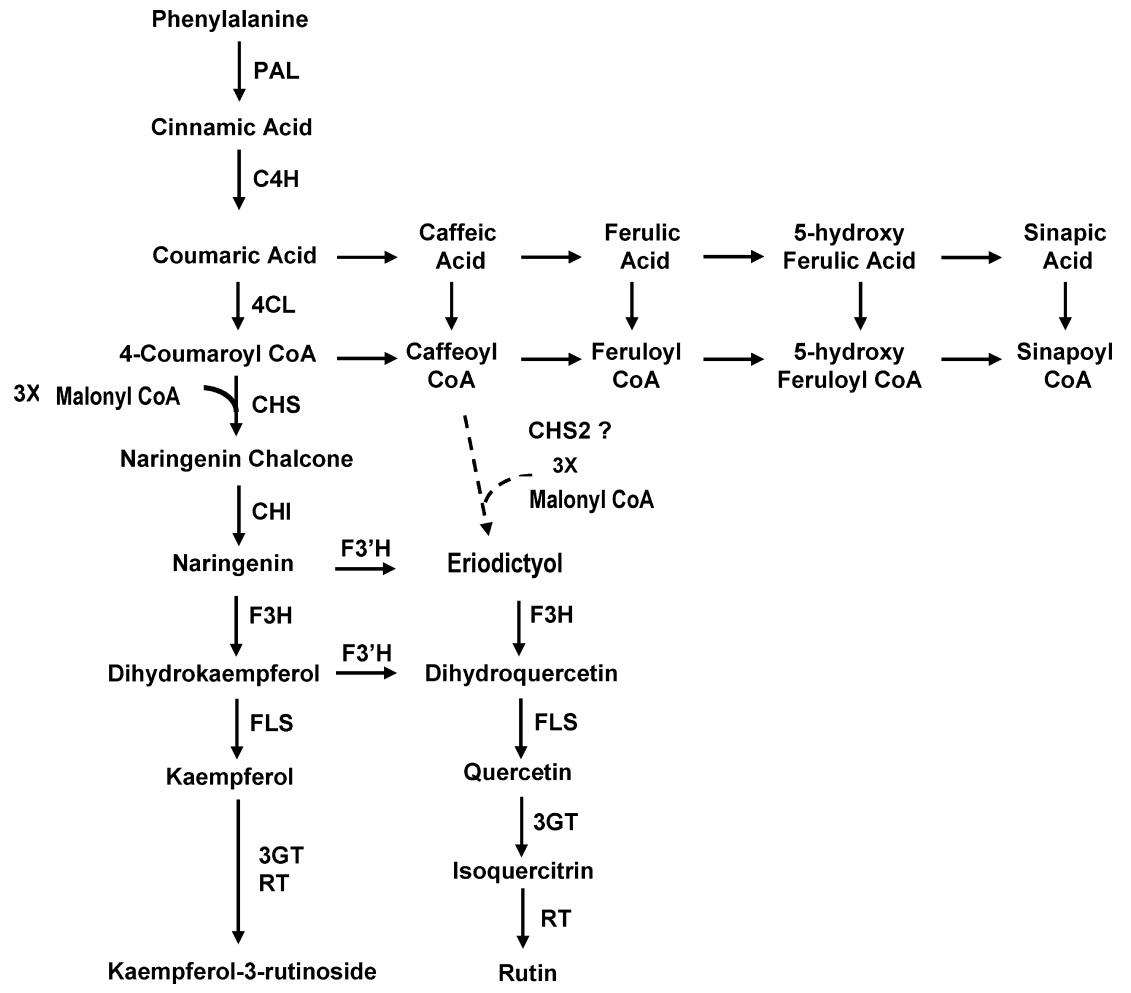

Figure 6. Schematic pathway for flavonoid and hydroxycinnamic acid biosynthesis. Only flavonoids, hydroxycinnamic acids, and enzymes relevant to this work are indicated. PAL, phenylalanine-ammonia lyase; $\mathrm{C} 4 \mathrm{H}$, cinnamic acid 4-hydrolase; $4 \mathrm{CL}$, 4-coumarate-CoA ligase; $\mathrm{CHS}$, chalcone synthase; $\mathrm{CH}$, chalcone isomerase; F3H, flavanone 3-hydroxylase; F3'H, flavanone 3'-hydroxylase; DFR, dihydroflavonol reductase; FLS, flavonol synthase; 3GT, 3-O-glucosyltransferase; RT, rhamnosyltransferase. The hypothetical tomato CHS enzyme with substrate preference for feruloyl-CoA and caffeoyl-CoA, instead of coumaroyl-CoA, is indicated with the dotted line.

times higher in comparison to the control at MG stage. Both the remarkable $C H S$ transcript increase and the modest one of its downstream $F 3 H, F 3^{\prime} H$, and $F L S$ transcripts in UV-Bshielded fruits (Figure 3B) correlated to the dramatic raise of naringenin chalcone amount and the modest increase of quercetin measured in the flesh at the TU stage (Figure 3A), thus suggesting that, although the downstream structural genes are significantly more expressed in the absence of UV-B, at least in one of the ripening stages, the $C H I$ expression level represented a limiting factor for the synthesis of quercetin and rutin also in UV-B-shielded fruits.

In Esperanza, the UV-B-shielded peel showed a severe delay in the activation of the $C H S, F 3 H$, and $F L S$ genes compared to control peel together with a late reactivation at the RR stage of $\mathrm{CHI}$ and $\mathrm{F3}^{\prime} \mathrm{H}$ (Figure 4B). Accordingly, a significant increase of rutin and 3-quercetin pentosylrutinoside at the expense of naringenin chalcone was observed at the RR stage (Figure 4A).

In Esperanza flesh, the $\mathrm{CHS}$ and $\mathrm{CHI}$ genes were both enhanced in UV-B-shielded fruits and more significantly at the TU stage, whereas FLS was activated early, at the MG stage, in UV-B-shielded fruits (Figure 4B). Although the $F 3 H$ and $F 3^{\prime} H$ transcript level was reduced in UV-B-shielded fruits, the enhancement of $C H S$ and particularly of the limiting step $C H I$ clearly accounts for the great enhancement of all flavonoids detected in the flesh of Esperanza UV-Bshielded fruits (Figure 4A).

It is interesting to show how UV-B depletion affected the carotenoid accumulation measured in the whole fruits (26) in a similar fashion as they did on flavonoids in DRW 5981 peel and in both Esperanza peel and flesh, suggesting a possible common upstream regulatory mechanism for their biosynthesis or, at least, their possible involvement in similar physiological processes despite their different nature and accumulation sites.
In conclusion, our analyses showed that flavonoid and hydroxycinnamic acid biosynthesis was strongly affected by light conditions and, especially, by ultraviolet radiation at the gene expression level, resulting in a different content of the respective metabolites. More specifically, the DRW 5981 flavonoid metabolism, generally, appeared to be stimulated by the presence of the UV-B radiation (Figure 3A), whereas in Esperanza flavonoids accumulated at a higher level in UV-Bshielded fruits (Figure 4A). Moreover, our data indicated that the use of specific plastic covers able to eliminate UV-B radiation may be an environmentally friendly approach to modulate the expression of structural genes also in flesh of specific cultivars, such as Esperanza, and subsequently to enhance healthy antioxidant compounds in tomato fruits, whereas open-field cultivation is suggested for other cultivars such as DRW 5981.

Further studies are thus required to investigate the transcriptome-metabolome of tomato fruit subjected to UV-B depletion, by analyzing the accumulation pattern of other minor phenolic compounds, such as kaempferol and its derivatives as well as naringenin derivatives. Moreover, the expression of other structural genes of the phenylpropanoid metabolism will be further studied in order to better understand the UV-light response of the phenolic pathway in tomato.

\section{ABBREVIATIONS USED}

UV-B, ultraviolet B; MG, mature green; TU, turning; RR, red ripe; $C H S$, chalcone synthase; $C H I$, chalcone isomerase; $F 3 H$, flavanone 3-hydroxylase; $F 3^{\prime} H$, flavanone 3 '-hydroxylase; FLS, flavonol synthase; RT-PCR, reverse transcription-polymerase chain reaction. 


\section{ACKNOWLEDGMENT}

We are very thankful to Professor Bartolomeo Lercari of the Dipartimento di Coltivazione delle Piante Agrarie, Sezione di Orticoltura, Università di Pisa, for his valuable advice and for letting us grow our plants in his department.

\section{LITERATURE CITED}

(1) Duthie, G.; Crozier, A. Plant-derived phenolic antioxidants. Curr. Opin. Lipidol. 2000, 11, 43-47.

(2) Pietta, P. Flavonoids as antioxidants. J. Nat. Prod. 2000, 63, 10351042.

(3) Hertog, M. G.; Feskens, E. J.; Kromhout, D. Antioxidant flavonols and coronary heart disease risk. Lancet 1997, 349, 699.

(4) Knekt, P.; Jarvinen, R.; Seppanen, R.; Hellovaara, M.; Teppo, L.; Pukkala, E.; Aromaa, A. Dietary flavonoids and the risk of lung cancer and other malignant neoplasms. Am. J. Epidemiol. 1997, 146, 223-230.

(5) Commenges, D.; Scotet, V.; Renaud, S.; Jacqmin-Gadda, H.; Barberger-Gateau, P.; Dartigues, J. F. Intake of flavonoids and risk of dementia. Eur. J. Epidemiol. 2000, 16, 357-363.

(6) Yamamoto, T.; Yoshimura, M.; Yamaguchi, F.; Kouchi, T.; Tsuji, R.; Saito, M.; Obata, A.; Kikuchi, M. Anti-allergic activity of naringenin chalcone from a tomato skin extract. Biosci. Biotechol. Biochem. 2004, 68, 1706-1711.

(7) Nijveldt, R. J.; van Nood, E.; van Hoorn, D. E. C.; Boelens, P. G.; van Norren, K.; van Leeuwen, P. A. M. Flavonoids: a review of probable mechanism of action and potential application. Am. J. Clin. Nutr. 2001, 74, 418-425.

(8) Suesslin, C.; Frohnmeyer, H. An Arabidopsis mutant defective in UV-B-mediated responses. Plant J. 2003, 33, 591-601.

(9) Oravecz, A.; Baumann, A.; Mate, Z.; Brzezinska, A.; Molinier, J.; Oakeley, E. J.; Adam, E.; Shafer, E.; Nagy, F.; Ulm, R. CONSTITUTIVELY PHOTOMORPHOGENIC1 is required for the UV-B response in Arabidopsis. Plant Cell 2006, 18, 19751990.

(10) Brown, B. A.; Cloix, C.; Jiang, G. H.; Kaiserli, E.; Herzyk, P.; Kliebenstein, D. J.; Jenkins., G. I. A. UV-B-specific signaling component orchestrates plant UV protection. Proc. Natl. Acad. Sci. U.S.A. 2005, 102, 18225-18230.

(11) Ulm, R.; Baumann, A.; Oravecz, A.; Mate, Z.; Adam, E.; Oakeley, E. J.; Shafer, E.; Nagy, F. Genome-wide analysis of gene expression reveals function of the bZIP transcription factor HY5 in the UV-B response of Arabidopsis. Proc. Natl. Acad. Sci. 2004, 101, 1397-1402.

(12) Fuglevand, G.; Jackson, J. A.; Jenkins, G. I. UV-B, UV-A, and blue light signal transduction pathways interact synergistically to regulate chalcone synthase gene expression in Arabidopsis. Plant Cell 1996, 8, 2347-2357.

(13) Bovy, A.; van den Berg, C.; de Vrieze, G.; Thompson, W. F.; Weisbeek, P.; Smeekens, S. Light-regulated expression of the Arabidopsis thaliana ferredoxin gene requires sequences upstream and downstream of the transcription initiation site. Plant Mol. Biol. 1995, 27, 27-39.

(14) Winkel-Shirley, B. Biosynthesis of flavonoids and effect on stress. Curr. Opin. Plant Biol. 2000, 5, 218-223.

(15) Brosché, M.; Strid, A. Molecular events following perception of ultraviolet-B radiation by plants. Physiol. Plant. 2003, 117, 110.

(16) Li, J.; Ou-Lee, T. M.; Raba, R.; Amundson, R. G.; Last, R. L. Arabidopsis flavonoid mutants are hypersensitive to UV-B irradiation. Plant Cell 1993, 5, 171-179.

(17) Bieza, K.; Lois, R. An Arabidopsis mutant tolerant to lethal ultraviolet-B levels shows constitutively elevated accumulation of flavonoids and other phenolics. Plant Physiol. 2001, 126, 11051115 .

(18) Sheahan, J. J. Sinapate esters provide greater UV-B attenuation than flavonoids in Arabidopsis thaliana (Brassicaceae). Am. J. Bot. 1996, 83, 679-686.
(19) Muir, S. R.; Collins, G. J.; Robinson, S.; Hughes, S.; Bovy, A.; De Vos, C. H. R.; van Tunen, A. J.; Verhoeyen, M. E. Overexpression of petunia chalcone isomerase in tomato results in fruit containing increased levels of flavonols. Nat. Biotechnol. 2001, 19, 470-474.

(20) Willits, M. G.; Kramer, C. M.; Prata, R. T. N.; De Luca, V.; Potter, B. G.; Steffens, J. C.; Graser, G. Utilization of the genetic resources of wild species to create a nontransgenic high flavonoid tomato. J. Agric. Food Chem. 2005, 53, 1231-1236.

(21) Verhoeyen, M. E.; Bovy, A.; Collins, G.; Muir, S.; Robinson, S.; de Vos, C. H. R.; Colliver, S. Increasing antioxidant levels in tomatoes through modification of the favonoid biosynthetic pathway. J. Exp. Bot. 2002, 53, 2099-2106.

(22) Schijlen, E.; de Vos, C. H. R.; Jonker, H.; van den Broek, H.; Molthoff, J.; van Tunen, A.; Martens, S.; Bovy, A. Pathway engineering for healthy phytochemicals leading to the production of novel flavonoids in tomato fruit. Plant Biotechnol. J. 2006, 4, 433-444.

(23) Bovy, A.; de Vos, R.; Kemper, M.; Schijlen, E.; Almenar Pertejo, M.; Muir, S.; Collins, G.; Robinson, S.; Verhoeyen, M.; Hughes, S.; Santos-Buelga, C.; van Tunen, A. Highflavonol tomatoes resulting from the heterologous expression of the maize transcription factor genes LC and C1. Plant Cell. 2002, 14, 2509-2526.

(24) Beggs, C. J.; Wellmann, E. Photocontrol of flavonoid biosynthesis. In Photomorphogenesis in plants, 2nd ed.; Kendrick, R. E., Kronenberg, G. H. M., Eds.; Kluwer Academic Publishers: Norwell, MA, 1994; pp 733-752.

(25) Ulm, R.; Nagy, F. Signalling and gene regulation in response to ultraviolet light. Curr. Opin. Plant Biol. 2005, 8, 477-482.

(26) Giuntini, D.; Graziani, G.; Lercari, B.; Fogliano, V.; Soldatini, G. F.; Ranieri, A. Changes in carotenoid and ascorbic acid contents in fruits of different tomato genotypes related to the depletion of UV-B radiation. J. Agric. Food Chem. 2005, 53, 3174-3181.

(27) Grierson, D.; Kader, A. A. Fruit ripening and quality. In The Tomato Crop; Atherton, J., Rudich, G., Eds.; Chapman and Hall: London, 1986; pp 241-280.

(28) Crozier, A.; Lean, M. E. J.; McDonald, M. S.; Black, C. Quantitative analysis of the flavonoid content of commercial tomatoes, onions, lettuce, and celery. J. Agric. Food Chem. 1997, 45, 590-595.

(29) Rapisarda, P.; Carollo, G.; Fallico, B.; Tomaselli, F.; Maccarone, E. Hydroxycinnamic acids as markers of italian blood orange juices. J. Agric. Food Chem. 1998, 46, 464-470.

(30) Le Gall, G.; DuPont, M. S.; Mellon, F. A.; Davis, A. L.; Collins, G. J.; Verhoeyen, M. E.; Colquhoun, I. J. Characterization and content of flavonoid glycosides in genetically modified tomato (Lycopersicon esculentum) fruits. J. Agric. Food Chem. 2003, 51, 2438-2446.

(31) Le Gall, G.; Colquhoun, I. J.; Davis, A. L.; Collins, G. J.; Verhoeyen, M. E. Metabolite profiling of tomato (Lycopersicon esculentum) using ${ }^{1} \mathrm{H}$ NMR spectroscopy as a tool to detect potential unintended effects following a genetic modification. $J$. Agric. Food Chem. 2003, 51, 2447-2456.

(32) Cuyckens, F.; Claeys, M. Mass spectrometry in the structural analysis of flavonoids. J. Mass. Spectrom. 2004, 39, 1-15.

(33) Moco, S.; Capanoglu, E.; Tikunov, Y.; Bino, R. J.; Boyacioglu., D.; Hall., R. D. ; Vervoort., J. ; De Vos., R. C. H. Tissue specialization at the metabolite level is perceived during the development of tomato fruit. J. Exp. Bot. 2007, 58, 41314146.

(34) Slimestad, R.; Fossen, T.; Verheul, M. J. The flavonoids of tomatoes. J. Agric. Food. Chem. 2008, in press (DOI 10.1021/ jf073434n).

(35) Stewart, A. J.; Bozonnet, S.; Mullen, W.; Jenkins, G. I.; Lean, M. E. J.; Crozier, A. Occurrence of flavonols in tomatoes and tomato-based products. J. Agric. Food Chem. 2000, 48, 2663-2669. 
(36) Caris-Veyrat, C.; Amiot, M.-J.; Tyssandier, V.; Grasselly, D.; Buret, M.; Mikolajczak, M.; Guilland, J.-C.; Bouteloup-Demange, C.; Borel, P. Influence of organic versus conventional agricultural practice on the antioxidant microconstituent content of tomatoes and derived purees; consequences on antioxidant plasma status in humans. J. Agric. Food Chem. 2004, 52, 6503-6509.

(37) Torres, C. A.; Davies, N. M.; Yanez, J. A.; Andrews, P. K. Disposition of selected flavonoids in fruit tissues of various tomato (Lycopersicon esculentum Mill.) genotypes. J. Agric. Food Chem. 2005, 53, 9536-9543.

(38) Peng, Y.; Zhang, Y.; Ye, J. Determination of phenolic compounds and ascorbic acid in different fractions of tomato by capillary electrophoresis with electrochemical detection. J. Agric. Food Chem. 2008, 56, 1838-1844.

(39) Markham, K. R.; Ryan, K. G.; Stephen, J. B.; Mitchell, K. A. An increase in the luteolin:apigenin ratio in Marchantia polymorpha on UV-B enhancement. Phytochemistry 1998, 48, 791-794.

(40) Markham, K. R.; Tanner, G. J.; Caasi-Lit, M.; Whitecross, M. I.; Nayudu, M.; Mitchell, K. A. Possible protective role for $3^{\prime}, 4^{\prime}$-dihydroxyflavones induced by enhanced UV-B in a UV-tolerant rice cultivar. Phytochemistry 1998, 49, 1913-1919.

(41) Hartmann, U.; Sagasser, M.; Mehrtens, F.; Stracke, R.; Weisshaar, B. Differential combinatorial interactions of cisacting elements recognized by R2R3-MYB, BZIP, and BHLH factors control light-responsive and tissue-specific activation of phenylpropanoid biosynthesis genes. Plant Mol. Biol. 2005, 47, 155-171.
(42) Winkel-Shirley, B. Flavonoid biosynthesis. A colorful model for genetics, biochemistry, cell biology, and biotechnology. Plant Physiol. 2001, 126, 485-493.

(43) Burbulis, I. E.; Winkel-Shirley, B. Interactions among enzymes of the Arabidopsis flavonoid pathway. Proc. Natl. Acad. Sci. U.S.A. 1999, 96, 12929-12934.

(44) Ralston, L.; Subramanian, S.; Matsuno, M.; Yu, O. Partial reconstruction of flavonoid and isoflavonoid biosynthesis in yeast using soybean type I and type II chalcone isomerases. Plant Physiol. 2005, 137, 1375-1388.

(45) Christensen, A. B.; Gregersen, P. L.; Shröeder, J.; Collinge, D. B. A chalcone synthase with an unusual substrate preference is expressed in barley leaves in response to UV light and pathogen attack. Plant Mol. Biol. 1998, 37, 849-857.

(46) Schroder, J.; Schroder, G. Stilbene and chalcone synthases: related enzymes with key functions in plant-specific pathways. $Z$. Naturforsch. 1990, 45, 1-8.

Received for review February 1, 2008. Revised manuscript received April 3, 2008. Accepted April 10, 2008. This study was supported by a grant from the Ministero dell'Università e della Ricerca (National Project) Rome, Italy, to A.R. and K.P.; by the European Union Framework Programme VI FLORA Project (FOOD-CT-2005007130) to C.T.; and by funds of the University of Pisa to A.R.

JF8003338 